\title{
THROMBOXANE $B_{2}$ INHIBITS THE PULMONARY INACTIVATION OF PROSTAGLANDIN $E_{2}$ IN THE DOG
}

\author{
THOMAS M. FITZPATRICK, LAWRENCE S. FRIEDMAN, PETER A. KOT \\ \& PETER W. RAMWELL
}

Georgetown University Medical Center, Department of Physiology and Biophysics, 3900 Reservoir Road, N.W., Washington, D.C. 20007, U.S.A.

1 The systemic vasodepressor response to intravenously administered prostaglandin $E_{2}\left(\mathrm{PGE}_{2}, 0.3\right.$, 1.0 and $3.0 \mu \mathrm{g} / \mathrm{kg})$ is potentiated during intravenous infusion of thromboxane $\mathrm{B}_{2}\left(\mathrm{TXB}_{2}, 1.0 \mu \mathrm{g} \mathrm{kg}^{-1}\right.$ $\min ^{-1}$ ) in the anaesthetized dog.

2 The augmented haemodynamic response returns toward control values following cessation of the $\mathrm{TXB}_{2}$ infusion.

3 The systemic haemodynamic responses to intra-arterially administered $\mathrm{PGE}_{2}, \mathrm{PGF}_{2 \alpha}$ and $\mathrm{PGI}_{2}$ as well as intravenously administered $\mathrm{PGF}_{2 \alpha}$ and $\mathrm{PGI}_{2}$ are not altered by $\mathrm{TXB}_{2}$ infusion.

4 This study suggests that $\mathrm{TXB}_{2}$ inhibits the pulmonary inactivation of $\mathrm{PGE}_{2}$.

5 Arachidonic acid metabolites may interact, producing haemodynamic responses differing from their individual effects.

\section{Introduction}

Prostaglandin $\mathrm{E}_{2}\left(\mathrm{PGE}_{2}\right)$, a product of prostaglandin endoperoxide $\left(\mathrm{PGG}_{2}\right.$ and $\left.\mathrm{PGH}_{2}\right)$ isomerization, depresses systemic arterial pressure (SAP) by directly dilating the resistance vessels of the circulation (Nakano \& McCurdy, 1967; Malik \& McGiff, 1976). Since $\mathrm{PGE}_{2}$ is approx. $90 \%$ inactivated by a single passage through the pulmonary circulation (Ferreira \& Vane, 1967) the magnitude of hypotension is dependent upon its route of administration or site of its synthesis. The lungs, therefore, play a strategic role in regulating the concentration of $\mathrm{PGE}_{2}$ reaching the heart and systemic vasculature.

In addition, depending upon the stimuli, endoperoxides may be converted to several other compounds. Thromboxane $\mathrm{A}_{2}\left(\mathrm{TXA}_{2}\right)$, a potent platelet aggregator and constrictor of vascular smooth muscle (Hamberg, Svensson \& Samuelsson, 1975), is a potential product of endoperoxide transformation. Due to structural instability however $\left(T_{\frac{1}{2}}=32 \mathrm{~s}\right.$ in aqueous solution), $\mathrm{TXA}_{2}$ quickly converts to the more stable thromboxane $\mathrm{B}_{2}\left(\mathrm{TXB}_{2}\right)$ (Hamberg et al., 1975). It was recently demonstrated that $\mathrm{TXB}_{2}$ inhibited the pulmonary degradation of $\mathrm{PGE}_{2}$ when infused through the rat isolated lung (Boura \& Murphy, 1978a). Since there is a probable concomitant release of $\mathrm{PGE}_{2}$ and $\mathrm{TXB}_{2}$ by the lung during anaphylaxis (Anggard \& Samuelsson 1965; Palmer, Piper \& Vane, 1973; Dawson, Boot, Cockerill, Mallen \& Osborn, 1976; Crutchley, Piper \& Seale, 1977) and endotoxin shock (Dusting, Moncada \& Vane, 1979) we investi- gated whether interaction between $\mathrm{TXB}_{2}$ and $\mathrm{PGE}_{2}$ occurs in the lungs of intact anaesthetized dogs.

\section{Methods}

Mongrel dogs (15 to $20 \mathrm{~kg}$ ) of either sex were anaesthetized with intravenous sodium pentobarbitone $(30$ $\mathrm{mg} / \mathrm{kg}$ ). Airway patency was maintained with a cuffed endotracheal tube. A Swan-Ganz catheter was positioned in the pulmonary artery. The distal lumen of this catheter was used for monitoring pulmonary arterial pressure (PAP) and the proximal lumen for injecting test compounds intravenously (i.v.). The right femoral artery was catheterized for measurement of systemic arterial blood pressure. A Cordis 'pig-tail' catheter was inserted through the left femoral artery into the left ventricle for the intra-arterial (i.a.) administration of test compounds. The left femoral vein was catheterized and used for $\mathrm{TXB}_{2}$ infusion.

The extent of $\mathrm{PGE}_{2}$ inactivation by the lung was determined by measuring the SAP response to intravenous and intra-arterial $\mathrm{PGE}_{2}$ administered before and during $\mathrm{TXB}_{2}$ infusion $\left(1 \mu \mathrm{g} \mathrm{kg}{ }^{-1} \mathrm{~min}^{-1}\right)$. Neglecting its own metabolism, we estimated that the $\mathrm{TXB}_{2}$ blood concentration after a $30 \mathrm{~min}$ infusion to be less than $400 \mathrm{ng} / \mathrm{ml}$. This $\mathrm{TXB}_{2}$ concentration alone produced no change in SAP or PAP.

Initially, control systemic arterial pressure responses to intravenous $(0.3,1.0$ and $3.0 \mu \mathrm{g} / \mathrm{kg})$ and 


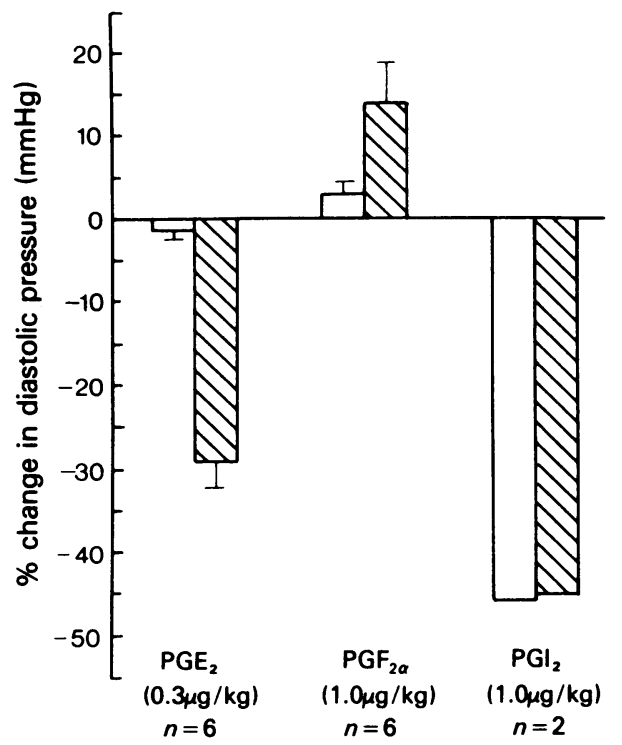

Figure 1 A comparison of the control responses to prostaglandin $\mathrm{E}_{2}\left(\mathrm{PGE}_{2}^{*}\right), \mathrm{PGF}_{2 \alpha}^{*}$ and $\mathrm{PGI}_{2}$, when administered by intravenous (open columns) and intraarterial (hatched columns) routes. Vertical bars represent s.e. mean *Significant at $P<0.05$.

intra-arterial $(0.03,0.1$ and $0.3 \mu \mathrm{g} / \mathrm{kg}) \mathrm{PGE}_{2}(n=16)$ were obtained. For purposes of comparison, intravenous $(1.0 \mu \mathrm{g} / \mathrm{kg})$ and intra-arterial $(1.0 \mu \mathrm{g} / \mathrm{kg}) \mathrm{re}-$ sponses to $\mathrm{PGI}_{2}(n=2)$ and $\mathrm{PGF}_{2 \alpha}(n=6)$ were also measured.

In order to establish whether the effect of $\mathbf{T X B}_{2}$ was reversible, $\mathrm{PGE}_{2}(n=6)($ i.v. $1 \mu \mathrm{g} / \mathrm{kg})$ was administered at $5 \mathrm{~min}$ intervals following termination of the $\mathrm{TXB}_{2}$ infusion.

Stock solutions of $\mathrm{TXB}_{2}, \mathrm{PGI}_{2}, \mathrm{PGE}_{2}$ and $\mathrm{PGF}_{2 \alpha}$ were prepared in ethanol $(1 \mathrm{mg} / \mathrm{ml})$ and stored at $-20^{\circ} \mathrm{C}$. Solutions of $\mathrm{PGE}_{2}, \mathrm{PGF}_{2 \alpha}$ and $\mathrm{PGI}_{2}$ were dried under nitrogen and diluted to concentrations of $10 \mu \mathrm{g} / \mathrm{ml}$ (i.a. $\mathrm{PGE}_{2}$ ) and $100 \mu \mathrm{g} / \mathrm{ml}\left(\mathrm{PGI}_{2}, \mathrm{PGF}_{2 \alpha}\right.$ and intravenous $\mathrm{PGE}_{2}$ ) with isotonic saline. $\mathrm{TXB}_{2}$ was prepared in a similar manner at concentrations that varied in proportion to the weight of the dog.

Data were analyzed by Student's $t$ test for paired data. A $P<0.05$ was considered significant.

\section{Results}

Control percentage changes in systemic arterial diastolic blood pressure to intravenously and intraarterially administered $\mathrm{PGE}_{2}, \mathrm{PGF}_{2 \alpha}$ and $\mathrm{PGI}_{2}$ are compared in Figure 1. $\mathrm{PGE}_{2}$ responses, compared at $0.3 \mu \mathrm{g} / \mathrm{kg}$, represent the only common intravenous and intra-arterial dose level employed. The systemic

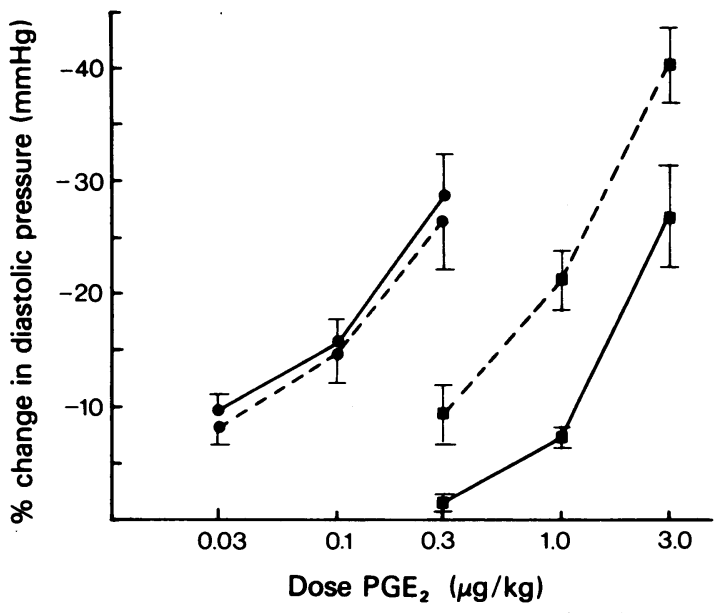

Figure 2 Log dose-responses to prostaglandin $E_{2}$ $\left(\mathrm{PGE}_{2}\right)$ administered intravenously $(\boldsymbol{\square})$ and intraarterially (O) before (-) and during (-..-) infusion of thromboxane $\mathbf{B}_{2}$. Vertical bars represent s.e. mean.

hypotensive action of $\mathrm{PGI}_{2}$ was the same by either route of administration. In contrast, both $\mathrm{PGE}_{2}$ and PGF $_{2 \alpha}$ elicited a significantly $(P<0.05)$ greater response when administered intra-arterially.

Figure 2 shows the log dose-responses to intravenous and intra-arterial administration of $\mathrm{PGE}_{2}$ before and during the infusion of $\mathrm{TXB}_{2}$. The systemic depressor response to intravenous $\mathrm{PGE}_{2}$ was significantly $(P<0.05)$ augmented at each of the three dose levels tested. However, the log dose-responses to intra-arterial administration of $\mathrm{PGE}_{2}$ were unaffected by the $\mathrm{TXB}_{2}$ infusion.

To determine whether the effect of $\mathrm{TXB}_{2}$ was specific for $\mathrm{PGE}_{2}$, the systemic arterial diastolic pressure responses to $\mathrm{PGE}_{2}, \mathrm{PGF}_{2 \alpha}$ and $\mathrm{PGI}_{2}$ were compared before and during $\mathrm{TXB}_{2}$ infusion. Figure 3 illustrates the percentage change in arterial diastolic pressure elicited by intravenous bolus injections (1.0 $\mu \mathrm{g} / \mathrm{kg}$ ) of each of the three test compounds. Only the systemic arterial diastolic pressure response of $\mathrm{PGE}_{2}$ was significantly $(P<0.05)$ augmented during $\mathrm{TXB}_{2}$ infusion.

The ability of $\mathrm{TXB}_{2}$ to potentiate the systemic hypotensive action of intravenously administered $\mathrm{PGE}_{2}$ was rapidly reversible. In six animals $\mathrm{PGE}_{2}$ $(1.0 \mu \mathrm{g} / \mathrm{kg})$ was administered before, during and at 5 min intervals following termination of the $\mathrm{TXB}_{2}$ infusion. Within 5 min after stopping the $\mathrm{TXB}_{2}$ infusion, the systemic depressor response elicited by $\mathrm{PGE}_{2}$ was significantly $(P<0.05)$ diminished and continued to be reduced during the subsequent 15 min (Figure 4). At $20 \mathrm{~min}$ after the end of the $\mathrm{TXB}_{2}$ infusion, the $\mathrm{PGE}_{2}$ response was not significantly different from control. 


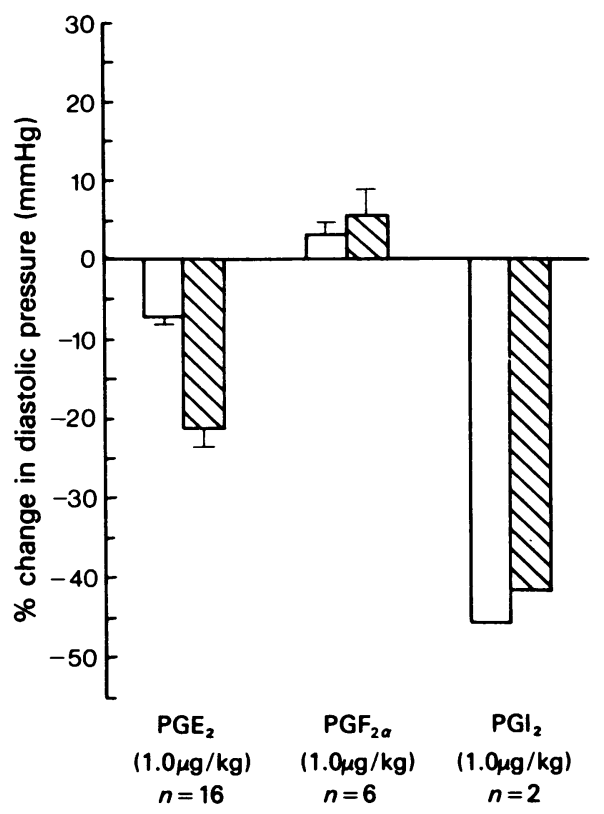

Figure 3 Comparison of response to intravenously administered prostaglandin $\mathrm{E}_{2}\left(\mathrm{PGE}_{2}^{*}\right), \mathrm{PGF}_{2 \alpha}$ and $\mathrm{PGI}_{2}$ before (open columns) and during (hatched columns) infusion of thromboxane $\mathrm{B}_{2}\left(\mathrm{TXB}_{2}\right)$. The difference in $\mathrm{PGF}_{2 \alpha}$ response is not significant. Vertical bars represent s.e. mean ${ }^{*}$ Significant at $P<0.05$.

\section{Discussion}

The magnitude of the systemic arterial depressor response to $\mathrm{PGE}_{2}$ when administered intra-arterially is normally several times greater than the response elicited by an equivalent dose administered intravenously (Waldman, Alter, Kot, Rose \& Ramwell, 1978). The i.a.-i.v. difference is explained by 15 -prostaglandin dehydrogenase (15-PGDH)-mediated degradation in the lung (Ferreira \& Vane, 1967; Anggard \& Samuelsson, 1967). 15-PGDH is not unique to the lung but its presence there is important in regulating the concentration of several prostaglandins that affect the heart and systemic circulation.

The present study demonstrates that the systemic vasodepressor response produced by intravenous $\mathrm{PGE}_{2}$ is augmented in the intact canine circulation during $\mathrm{TXB}_{2}$ infusion. The shift of the $\log$ doseresponse to intravenous $\mathrm{PGE}_{2}$ suggests that greater concentrations of this substance are reaching the systemic circulation.

However, $\mathrm{TXB}_{2}$ does not alter the vascular response to intra-arterially administered $\mathrm{PGE}_{2}$ and the duration of the potentiated $\mathrm{PGE}_{2}$ response was similar to that of the control response. Furthermore, peripheral inactivation of $\mathrm{PGE}_{2}$ appears to be unaffected by $\mathrm{TXB}_{2}$ and the potentiating action appears specific for $\mathrm{PGE}_{2}$ since $\mathrm{TXB}_{2}$ does not affect the SAP responses of $\mathrm{PGF}_{2 \alpha}$ and $\mathrm{PGI}_{2}$.

Induction of pulmonary $\mathrm{PGE}_{2}$ synthesis by $\mathrm{TXB}_{2}$ could account for the augmented vascular response that we observed. However, Boura \& Murphy (1978a) have demonstrated that $\mathrm{TXB}_{2}$ does not increase prostaglandin release when perfused through the isolated lung of the rat.

Reduced synthesis of the inactivating enzyme 15-PGDH could also account for the increased responsiveness to $\mathrm{PGE}_{2}$. For instance, rats pretreated with cycloheximide, an inhibitor of 15-PGDH synthesis, demonstrate a reduced inactivation of $\mathrm{PGE}_{2}$ (Boura \& Murphy, 1978b). Since the potentiated response to $\mathrm{PGE}_{2}$ is significantly reversed within $5 \mathrm{~min}$ after termination of the $\mathrm{TXB}_{2}$ infusion it seems unlikely that 15-PGDH synthesis could be inhibited and re-established within that short time.

$\mathrm{TXB}_{2}$ itself, is not a substrate for 15-PGDH (Roberts, Sweetman, Morgan, Payne \& Oates, 1977), yet it may interfere with the carrier-mediated intracellular prostaglandin transport mechanism postulated by Bito, Wallenstein \& Baroody (1976). Blockade, competition or saturation of this process in the pulmonary vasculature by $\mathrm{TXB}_{2}$ would potentiate intravenously administered $\mathrm{PGE}_{2}$. Probenecid, an organic acid transport inhibitor reduces the inactivation of $\mathrm{PGE}_{2}$ in the rat (Bito \& Baroody, 1975; Boura \& Murphy, 1978b) and dog lungs (Wicks, Ramwell, Kot \& Rose, 1978). In addition, clinical indicator dyes such as indocyanine green, sulphobromophthalein, phenol red, Evans blue, methylene blue and bromcresol green once considered inert compounds, inhibit $\mathrm{PGE}_{2}$ inactivation in isolated lung preparations of the rat (Bito \& Baroody, 1975; Bakhle, 1978).

Furthermore, although $\mathbf{P G I}_{2}$ is a substrate for 15-PGDH in lung homogenate (McGuire \& Sun, 1978) and intact liver (Wong, Sun \& McGiff, 1979) it is unaffected by transit through the pulmonary circulation (Dusting, Moncada \& Vane, 1978a). It has been postulated that a transmembrane transport system for $\mathrm{PGI}_{2}$ is lacking in the lung (Dusting, Moncada \& Vane, 1978b). This would explain why $\mathrm{TXB}_{2}$ did not affect the $\mathrm{PGI}_{2}$ vasodepressor response.

Whatever the mechanism by which $\mathrm{TXB}_{2}$ is acting, it is the first substance of endogenous origin found to be able to inhibit the pulmonary inactivation of $\mathrm{PGE}_{2}$ in an intact animal.

Prostacyclin is the major arachidonic acid metabolite produced by the lung under physiological conditions (Dusting et al., 1979; Mullane, Dusting, Salmon, Moncada \& Vane, 1979). There are circumstances however when the pulmonary production of other AA metabolites increases. Although elevated blood levels of $\mathrm{PGE}_{2}$ and $\mathrm{TXB}_{2}$ have yet to be conclusively measured simultaneously in the same ani- 


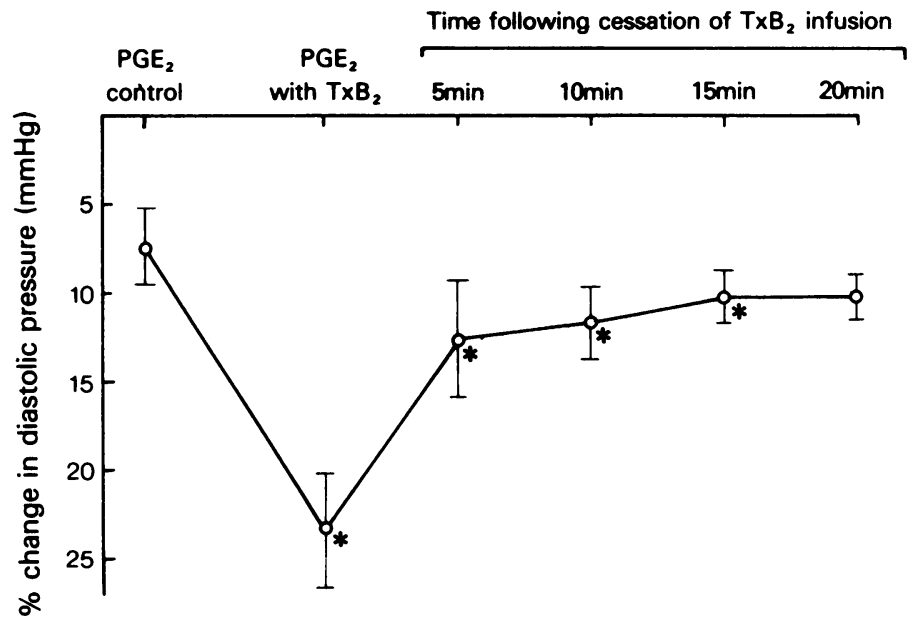

Figure 4 A comparison of the depressor response to prostaglandin $E_{2}\left(P E_{2}\right.$, i.v. $\left.1 \mu \mathrm{g} / \mathrm{kg}\right)$ before, during and at 5 min intervals following cessation of thromboxane $\mathbf{B}_{2}\left(\mathbf{T X B}_{2}\right)$ infusion. Vertical bars represent s.e. mean; $n=6$ *Significantly different from control at $P<0.05$.

mal, $\mathrm{PGE}_{2}$ is elevated in the dog (Anderson, Jibiz, Fralios, Tsagaris \& Kuida, 1972) and baboon (Fletcher, Ramwell \& Herman, 1976) following endotoxin shock. Frolich, Ogletree \& Brigham (1979) recently found a marked increase of TXB $_{2}(>200$ $\mathrm{ng} / \mathrm{ml}$ ) in the lung lymph of sheep and Harris, Zmudka, Maddox, Ramwell \& Fletcher (1979) reported elevated plasma $\mathrm{TXB}_{2}$ (maximum 2260 $\mathrm{ng} / \mathrm{ml}$ ) in the conscious baboon following endotoxin shock. These studies lead us to speculate that under some pathophysiological conditions, large enough quantities of $\mathrm{TXB}_{2}$ may be produced to inhibit partially the pulmonary degradation of $\mathrm{PGE}_{2}$. Their interaction would result in the augmented systemic hypotension we have observed.

In conclusion, our study demonstrates: (1) $\mathrm{TXB}_{2}$ augments the systemic vasodepressor response of in-

\section{References}

Anderson, F.L., Jibiz, W., Fralios, A.C., Tsagaris, T.J., \& KuIDA, H. (1972). Plasma prostaglandin levels during endotoxin shock in dogs. Circulation, 45, 11-124.

ANGGard, E. \& SAmuelsson, B. (1965). Biosynthesis of prostaglandins from arachidonic acid in guinea pig lung. Prostaglandins and related factors. J. biol. Chem., 240, 3518-3521.

ANGgard, E. \& Samuelsson, B. (1967). The metabolism of prostaglandins in lung tissue. In Nobel Symposium, Yol 2, Prostaglandins. ed Bergstrom, S. \& Samuelsson, B., New York: Interscience.

BAKHLE, Y.S. (1978). Clinically-used dyes are inhibitors of prostaglandin $E_{2}$ inactivation in the isolated lung. $B r$. J. Pharmac., 64, 386P. travenously administered $\mathrm{PGE}_{2}$ in the intact dog, (2) $\mathrm{TXB}_{2}$ appears to inhibit specifically the pulmonary inactivation of $\mathrm{PGE}_{2},(3)$ inhibition of $\mathrm{PGE}_{2}$ pulmonary degradation by $\mathrm{TXB}_{2}$ is reversible. Possibly of greatest significance, it is important to observe potential interactions between arachidonic acid metabolites. The biological activity of the combined compounds may differ from that of the individual components.

This work was supported by U.S.P.H.S. grant HL-18718 and U.S.P.H.S. Training grant HL-07213. We want to thank Yvonne Maddox, Debbie Holden and Stephen Moore for their technical assistance as well as Ellen Costello for her excellent editorial assistance and Amy Hogan for her secretarial skills.

$\mathrm{TXB}_{2}, \mathrm{PGF}_{2 \alpha}, \mathrm{PGI}_{2}$ and $\mathrm{PGE}_{2}$ were generously supplied by the Upjohn Company.

Bito, L.Z. \& BArOODY, R.A. (1975). Inhibition of pulmonary prostaglandin metabolism by inhibitors of prostaglandin biotransport (probenecid and bromcresol green). Prostaglandins, 10, 633-639.

Bito, L.Z., Wallenstein, M. \& Baroody, R. (1976). The role of transport processes in the distribution and disposition of prostaglandins. In Advances in Prostaglandin and Thromboxane Research, Vol 1, ed. Samuelsson, B. \& Paoletti, R. pp. 297-303. New York: Raven Press.

BOURA, A.L.A. \& MURPHY, R.D. (1978a). Thromboxane B $_{2}$ inhibits prostaglandin $E_{2}$ inactivation by the rat isolated perfused lung. Clin. exp. Pharmac. Physiol., 5, 387-392. 
BourA, A.L.A. \& MURPhy, R.D. (1978b). Some factors affecting inactivation of prostaglandin $\mathrm{E}_{2}\left(\mathrm{PGE}_{2}\right)$ by the rat isolated perfused lung. Br. J. Pharmac., 62 , 411P.

Crutchley, D.J., Piper, P.J. \& Seale, J.P. (1977). The nature of prostaglandin-like substances released from guinea-pig lungs in anaphylaxis. Eur. J. Pharmac., 44, 319-323.

Dawson, W., Boot, J.R., Cockerill, A.F., Mallen, D.N.B. \& OSBORN, D.J. (1976). Release of novel prostaglandins and thromboxanes after immunological challenge of guinea-pig lung. Nature, 262, 699-702.

Dusting, G.J., Moncada, S. \& Vane, J.R. (1978a). Disappearance of prostacyclin $\left(\mathrm{PGI}_{2}\right)$ in the circulation of the dog. Br. J. Pharmac., 62, 414P.

Dusting, G.J., Moncada, S. \& VANe, J.R. (1978b). Recirculation of prostacyclin $\left(\mathrm{PGI}_{2}\right)$ in the dog. Br. J. Pharmac., 64, 315-320.

Dusting, G.J., Moncada, S. \& Vane, J.R. (1979). Prostaglandins, their intermediates and precursors: cardiovascular actions and regulatory roles in normal and abnormal circulatory systems. Prog. Cardiovasc. Dis., 21, 405-430.

FerReira, S.H. \& VANE, J.R. (1967). Some factors affecting inactivation of prostaglandin $\mathrm{E}_{2}\left(\mathrm{PGE}_{2}\right)$ by the rat isolated perfused lung. Br. J. Pharmac., 62, 411P.

Fletcher, J.R., Ramwell, P.W. \& Herman, C.M. (1976). Prostaglandins and the hemodynamic course of endotoxin shock. J. Surg. Res., 20, 589-594.

Frolich, J.C., Ogletree, M., \& Bringham, K.L. (1979). Pulmonary hypertension correlated to pulmonary thromboxane synthesis. Fourth International Prostaglandin Conference, Washington, D.C. Abstract 38.

HamberG, M., Svensson, J. \& Samuelsson, B. (1975). Thromboxanes: A new group of biologically active compounds derived from prostaglandin endoperoxides. Proc. natn. Acad. Sci. U.S.A., 72, 2994-2998.

HarRis, R.H., ZMudKa, M., Maddox, Y., RamWell, P.W., \& FletCHER, J.R. (1979). Relationships of TXB T $_{2}$ and 6-keto-PGF ${ }_{1 x}$ to the hemodynamic changes during baboon endotoxic shock. In Advances in Prostaglandin and Thromboxane Research, Vol. 7, ed. Sammuelsson, B., Ramwell, P.W. \& Paoletti, R. pp. 843-849. New York: Raven Press.

MCGuIRE, J.C. \& SuN, F.F. (1978). Oxidation by Rhesus Monkey Lung 15-Hhydroxyl Prostaglandin Dehydrogenase. Arch. Biochem. Biophys., 189, 92-96.

Malik, K.U. \& McGiff, J.C. (1976). Cardiovascular actions of prostaglandins. In Advances in Prostaglandins. Physiological, Pharmacological and Pathological Aspects, Vol 3. ed. Karim, S.M.M. pp. 103-104. Lancaster: M.T.P. Press, Ltd.

Mullane, K.M., Dusting, G.J., Salmon, J.A., Moncada, S. \& VANE, J.R. (1979). Biotransformation and cardiovascular effects of arachidonic acid in the dog. Eur. $J$. Pharmac., 54, 217-228.

NaKano, J. \& McGurdy, J.R. (1967). Cardiovascular effects of prostaglandin $\mathrm{E}_{1}$.J. Pharmac. exp. Ther., 156, 538-547.

Palmer, M.A., Piper, P.J. \& Vane, J.R. (1973). Release of rabbit aorta contracting substance (RCS) and prostaglandins induced by chemical and mechanical stimulation of guinea-pig lungs. Br. J. Pharmac., 49, 226-242.

Roberts, L.J. 2d, Sweetman, B.J., Morgan, J.L., Payne, N.A. \& OATES, J.A. (1977). Identification of the major urinary metabolite of thromboxane $\mathrm{B}_{2}$ in the monkey. Prostaglandins, 13, 631-647.

Waldman, H.M., Alter, I., Kot, P.A., Rose, J.C. \& RamWELL, P.W. (1978). Effect of lung transit on systemic depressor responses to arachidonic acid and prostacyclin in dogs. J. Pharmac. exp. Ther., 204, 289-293.

Wicks, T.C., Ramwell, P.W., Kot, P.A. \& Rose, J.C. (1978). Inhibition of prostaglandin-induced pulmonary vasoconstriction by organic acid transport inhibitors. Proc. Soc. exp. Biol. Med., 157, 677-680.

Wong, P.Y.-K., Sun, F.F. \& McGiff, J.C. (1978). Metabolism of prostacyclin in blood vessels. J. biol. Chem., 253, 5555.

(Received September 7, 1979.) 